\title{
Autophagy in herpesvirus immune control and immune escape
}

\author{
Graham S Taylor ${ }^{1^{*}}$, Josef Mautner ${ }^{2^{*}}$, Christian Münz ${ }^{3^{*}}$
}

\begin{abstract}
Autophagy delivers cytoplasmic constituents for lysosomal degradation, and thereby facilitates pathogen degradation and pathogen fragment loading onto MHC molecules for antigen presentation to T cells. Herpesviruses have been used to demonstrate these novel functions of autophagy, which previously has been primarily appreciated for its pro-survival role during starvation. In this review, we summarize recent findings how macroautophagy restricts herpesvirus infections directly, how macroautophagy and chaperone mediated autophagy contribute to herpesviral antigen presentation on MHC molecules, and which mechanisms herpesviruses have developed to interfere with these pathways. These studies suggest that herpesviruses significantly modulate autophagy to escape from its functions in innate and adaptive immunity.
\end{abstract}

\section{Introduction}

Mammalian cells use primarily two proteolytic systems to catabolise intra- and extracellular material for energy and macromolecular building block generation. These are proteasomes and lysosomes. While proteasomes degrade soluble ubiquitinated proteins, lysosomes destroy ubiquitinated protein aggregates and cell organelles. Interestingly, these degradation mechanisms can also be used to eliminate pathogens and process their fragments for presentation to the immune system [1]. Access of substrates to these proteolytic, and in the case of lysosomes generally hydrolytic, machineries is tightly regulated by the 19 s cap complex for the proteasome, and endocytosis, vesicular sorting and autophagy for lysosomes.

In this context, autophagy delivers cytoplasmic constituents into lysosomes. Three autophagic pathways have been identified [2]. The first pathway, microautophagy, is a process in which substrates bud into the lysosomal lumen for degradation, but has thus far not been described in higher eukaryotes. The second pathway, chaperone mediated autophagy (CMA), transports proteins that contain a KFERQ like recognition sequence across the

\footnotetext{
* Correspondence: g.s.taylor@bham.ac.uk; mautner@helmholtz-muenchen.de; christian.muenz@usz.ch

'School of Cancer Sciences and Medical Research Council Centre for Immune Regulation, University of Birmingham, Birmingham, UK

${ }^{2}$ Department of Pediatrics, Technische Universität München and Helmholtz Zentrum München, German Research Center for Environmental Health,

Munich, Germany

Full list of author information is available at the end of the article
}

lysosomal membrane sequence into the lysosomal lumen. This transport is assisted by cytosolic and lysosomal chaperones as well as LAMP2a. The third pathway, macroautophagy, is currently the best characterised of the three. Macroautophagy employs 34 gene products, so called autophagy related (Atg) proteins, to construct a vesicle, the autophagosome, around its substrate and deliver it for fusion with lysosomes [3]. Autophagosomes are assembled from membranes of the rough endoplasmic reticulum, Golgi apparatus, outer nuclear or mitochondrial membrane, and the cell membrane [4-11]. Autophagosome assembly nucleates around type III phosphatidylinositol (PI) 3 kinase complexes, containing the PI3 kinase hVps34, hVps15, Atg14L and Atg6/Beclin-1 (Figure 1). Elongation of the autophagosome membrane to an isolation membrane is then achieved with the support of two ubiquitin-like systems. In one, Atg12 is activated by the E1-like enzyme Atg7 and then conjugated to Atg5 by the E2-like enzyme Atg10. The resulting conjugate then assembles with Atg16L1 and associates with the isolation membrane to function as an E3-like ligase for the other ubiquitin-like molecule Atg8 [12,13]. In the Atg8 ubiquitin-like conjugation system, Atg8 is first proteolytically processed by Atg4 to remove the five C-terminal amino acids and expose a $\mathrm{C}$-terminal glycine residue for ligation. Then Atg8 is activated by the E1-like enzyme Atg7 and transferred to the E2-like conjugating enzyme Atg3. It gets finally linked to phosphatidylethanolamine in the isolation membrane to mediate extension of the forming 


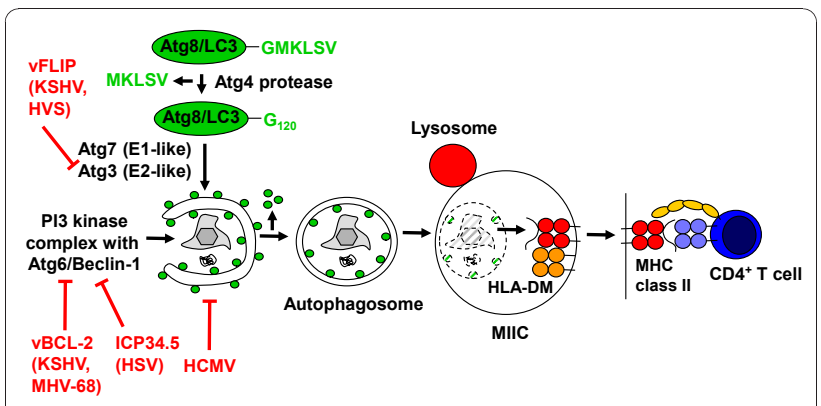

Figure 1 Immune escape from innate restriction and viral antigen presentation of herpesviruses by macroautophagy. $\alpha-, \beta$ - and $\gamma$-herpesviruses (herpes simplex virus [HSV], human cytomegalovirus [HCMV], Kaposi sarcoma associated herpesvirus [KSHV], herpesvirus saimiri [HVS] and murine herpesvirus 68 [MHV68]) inhibit macroautophagy by targeting either Atg6/Beclin-1 to prevent formation of the PI3 kinase complex, marking membranes with PI3 for the assembly of the autophagosome forming machinery, or Atg3, which mediates conjugation of the ubiquitinlike molecule Atg8/LC3, involved in autophagosomal membrane elongation and substrate recruitment. Incompleteness of these inhibitory mechanisms allows for viral particle degradation via lysosomal hydrolysis and antigen presentation on MHC class II molecules to $\mathrm{CD}^{+} \mathrm{T}$ cells.

autophagosome $[14,15]$. In addition, one mammalian homologue of Atg8, LC3, has been shown to anchor autophagosome cargo recruitment via p62/SQSTM1, NBR1 and NDP52 [16-19]. Isolation membrane extension leads eventually to the completion of the doublemembrane surrounded autophagosome, from whose outer membrane the Atg12 complex with Atg5 and Atg16L1, as well as Atg8 are recycled. Atg8, however, remains attached to the inner autophagosome membrane, and is degraded with the vesicle cargo. Completed autophagosomes can then fuse with late endosomes/multivesicular bodies (MVBs) or lysosomes. These fusion events are also supported or inhibited by PI3 kinase complexes containing Atg6/Beclin-1 and UVRAG or Rubicon instead of Atg14, respectively [20-22]. Fusion with lysosomes requires Rab7 and LAMP2 [23,24], while fusion with MVBs needs Rab11 [25]. In these compartments autophagosome cargo is then degraded by lysosomal hydrolases.

Of the three autophagy pathways, herpesvirus infection and their immune control have been shown to be regulated by macroautophagy. Therefore, we will concentrate in this review primarily on the influence of macroautophagy on herpesvirus infection in vivo, on $\mathrm{T}$ cell responses to herpesviruses and on immune escape mechanisms of herpesviruses that target this pathway.

\section{Restriction of herpesvirus infection by macroautophagy in vivo}

Regulation of herpesvirus infection by macroautophagy in vivo has primarily been investigated for herpes simplex virus type 1 (HSV-1), an $\alpha$-herpesvirus that causes a variety of clinical syndromes ranging from mild mucocutaneous disease to life-threatening viral encephalitis. In part, direct pathogen degradation by macroautophagy, termed "xenophagy", might be involved in this regulation. Early on it was recognized that HSV induces macroautophagy via double-stranded RNA-dependent protein kinase $\mathrm{R}$ (PKR), probably after recognizing convergently transcribed double-stranded RNA [26] and through activation of eukaryotic initiation factor (eIF) $2 \alpha$ [27]. While this is probably not the only pathway by which viruses stimulate macroautophagy $[28,29]$, in vivo evidence of the importance of PKR in the restriction of HSV infection in the central nervous system has been provided [30]. Moreover, HSV encodes infected cell protein 34.5 (ICP34.5), an important neurovirulence factor that plays a critical role in the development of fatal encephalitis in both mice and humans [31]. ICP34.5 can counteract PKR mediated HSV restriction and part of its function is blocking macroautophagy [32]. Indeed, recombinant HSV lacking only the macroautophagy inhibiting domain of ICP34.5 is less neurovirulent in mice [33]. HSV that cannot inhibit macroautophagy replicates to lower viral titers and causes less pathology. Again this restriction of ICP34.5 mutant HSV is PKR dependent and does not occur in PKR deficient mice. These data indicate that during cerebral HSV infection macroautophagy would control pathology and viral titers, should the virus not be able to block macroautophagy by its ICP34.5 protein. In addition to this interplay between HSV and macroautophagy during infection of the Central Nervous System (CNS), macroautophagy also affects vaginal HSV infection in mice. Deficiency of macroautophagy in dendritic cells (DCs) due to excision of Atg5 leads to elevated pathology and morbidity of intravaginally infected mice [34]. In combination, these data point towards roles for macroautophagy in the immune control of HSV in neurones as well as a wider systemic role in the priming of immune responses by DCs following intravaginal infection.

Apart from HSV, some in vivo data also exist for a role of macroautophagy inhibition in the growth of Kaposi sarcoma associated herpesvirus (KSHV) infected primary effusion lymphoma (PEL) cells in NOD/SCID mice. KSHV encoded vFLIP, a homolog of cellular FLICE-like inhibitor protein (cFLIP), blocks macroautophagy [35]. However, this inhibition can be compromised by dominant negative fragments of vFLIP, and these even attenuate PEL growth in vivo. Thus, KSHV seems to regulate macroautophagy to promote latently infected B cell growth in vivo.

\section{Herpesvirus antigen processing for MHC presentation by macroautophagy}

As described above, macroautophagy clearly plays an important role in the control of herpesvirus infection in 
vivo, possibly by orchestrating adaptive immunity in addition to just innately degrading pathogens. Along these lines, macroautophagy has now been shown to influence the adaptive immune response towards herpesviruses. By delivering portions of cytoplasm to lysosomes, macroautophagy provides a route for endogenous proteins to intersect vesicles that form an important part of the MHC class II processing pathway. These proteins are then degraded to generate peptide epitopes which, upon binding into the groove of trafficking MHC class II molecules, are transported to the cell surface for presentation to $\mathrm{CD}^{+} \mathrm{T}$ cells.

Formal demonstration that MHC class II peptide epitopes can be generated by macroautophagy came from studies in murine cells on the antigen processing of the mouse complement C5 protein [36]. The subsequent observation that an MHC class II epitope was processed from a bacterial protein by macroautophagy then clearly showed this pathway was not limited to self-proteins [37]. The first report of an MHC class II epitope being processed from a viral protein by macroautophagy came from studies on a herpesvirus protein. The $\gamma$-herpesvirus Epstein Barr virus (EBV) establishes life-long latent infection in MHC class II positive B cells which is maintained by its genome maintenance protein, EBV Nuclear Antigen 1 (EBNA1). Following inhibition of macroautophagy the recognition by EBNA1-specific CD4 ${ }^{+} \mathrm{T}$ cells of EBVtransformed B Lymphoblastoid Cell Lines (LCLs), which naturally express physiological levels of EBNA1, was reduced [38]. Interestingly, further work has since shown that ablating EBNA1's nuclear localization sequence (NLS), causing the protein to be present not just in the nucleus but also in the cytoplasm, increases the generation of $\mathrm{CD}^{+}{ }^{+} \mathrm{T}$ cell epitopes from EBNA1 by macroautophagy [39]. Restoration of nuclear localization, by the insertion of a heterologous NLS, decreased CD4 $4^{+} \mathrm{T}$ cell recognition demonstrating that it was indeed sub-cellular localization responsible for this effect. EBNA1, by virtue of its natural localization within the nucleus, enjoys a measure of protection from macroautophagy mediated degradation. Whether other viral nuclear antigens behave similarly remains to be determined.

The studies described above clearly show that macroautophagy is important in the processing of antigens in vitro. What then is the relevance of macroautophagy to the adaptive immune response in vivo? Mice that have had the essential macroautophagy gene atg5 conditionally deleted in their DCs, were less efficient at processing and presenting MHC class II epitopes from endogenous and exogenous antigens leading to impaired Th1 responses, while cross-presentation of exogenous antigens to $\mathrm{CD}^{+} \mathrm{T}$ cells was unaffected [34]. This study clearly demonstrates that macroautophagy plays an important role in the ability of DCs to process and present antigens to $\mathrm{CD} 4^{+} \mathrm{T}$ cells. However, the normal state of affairs is that viruses infect hosts that have an intact macroautophagy pathway in their immune cells. Given the importance of macroautophagy for the correct functioning of DCs (and therefore adaptive immunity as a whole) it would seem an obvious pathway to be targeted by viruses seeking to subvert immunity. Herpesviruses have evolved a variety of mechanisms to evade host immune responses and targeting autophagy can now be added to their repertoire. HSV-1 expressed ICP34.5 inhibits macroautophagy by binding the cellular protein Atg6/Beclin-1 [33]. Removal of the Beclin-1 binding domain from ICP34.5 did not affect HSV-1 replication in vitro, nor its neurovirulence in $\mathrm{Rag}^{-1-}$ mice that lack B and T cells [40]. However, neurovirulence was reduced in immunocompetent mice, a result suggesting that by binding Atg6/Beclin-1 and inhibiting macroautophagy, ICP34.5 interferes with the adaptive immune response to HSV. This was shown to be the case, with mice infected with the mutant virus (unable to inhibit macroautophagy) making much larger HSV-1 specific $\mathrm{CD}^{+} \mathrm{T}$ cell responses relative to mice infected with a control virus [40]. These studies suggest that macroautophagy enhances $\mathrm{CD}^{+} \mathrm{T}$ cell immunity in vivo by assisting viral antigen presentation on $\mathrm{MHC}$ class II molecules.

Another study using HSV has revealed that macroautophagy may be important for $\mathrm{CD}^{+} \mathrm{T}$ cell immunity as well. In murine macrophages infected with HSV-1, an $\mathrm{MHC}$ class I epitope from the gB protein was processed by the classic proteasomal pathway of antigen presentation during the early stages of infection, but by a vacuolar pathway at later stages [8]. As expected for HSV-1, macroautophagy was inhibited during the early stages of infection. However, at later stages the cells contained not only conventional autophagosomes in the cytoplasm, but also four-layered membrane structures connected to the nucleus; both were positive for LC3, a standard marker of autophagosomes. These unusual multi-membrane autophagosome structures were, like conventional autophagosomes, comprised of membranes from the endoplasmic reticulum and nucleus. The fact that these novel autophagosome structures were not seen in macrophages treated with drugs or stress to induce autophagy raises the possibility that this is a response to virus infection. Interestingly, only conventional autophagosomes were observed in cells infected with an HSV-1 mutant that, through deletion of the ICP34.5 gene, was unable to interfere with conventional macroautophagy. One possibility is that this unusual nuclear macroautophagy is a cellular response to a combination of HSV infection and macroautophagy blockade.

All the work described above has focused on macroautophagy as the mechanism of processing and presentation of 
viral antigens. It should, however, be noted that in this context other autophagy pathways could also potentially contribute. CMA has been less well studied, but this pathway has also been shown to be capable of generating $\mathrm{CD}^{+} \mathrm{T}$ cell epitopes from cellular proteins [41]. What about viral proteins in infected cells? Unlike macroautophagy, which is generally considered to be sequence unspecific, proteins degraded by CMA require a pentapeptide motif (KFERQ or a biochemically related sequence). Although this may at first seem to compromise CMA's value as an antigen processing pathway, it is important to note that KFERQ-like motifs occur frequently in proteins; for example, almost $30 \%$ of cellular proteins contain such a motif [42]. The chances that viruses lack a suitable motif in any of their proteins seem remote and it is likely only to be a matter of time before a virus epitope is shown to be generated by CMA. It will be interesting to see if any of the herpesviruses encode proteins that are substrates of CMA and, if so, whether they have also evolved countermeasures to this processing pathway.

Therefore, intracellular antigen processing for $\mathrm{MHC}$ class II presentation via autophagy has now been documented for macroautophagy and CMA. It, however, remains to be explored how autophagy can contribute to extracellular antigen processing and antigen packaging for cross-presentation [43].

\section{Immune escape from autophagy by herpesviruses}

Autophagy has recently been identified as an important intracellular effector mechanism of host immunity. By delivering intracellular bacteria and viruses to lysosomes for destruction via "xenophagy", and by importing viral nucleic acids to immune sensors in the endo/lysosomal compartment, macroautophagy plays a critical role in the defense against a number of chronic intracellular pathogens $[1,2,44]$. To ensure their own replication and to enhance their life cycle, many microbes have developed countermeasures and escape mechanisms to evade, subvert, or exploit macroautophagy, thereby adding to the cat-and-mouse game of microbial pathogenesis and host-pathogen interactions.

Given the intimate virus-host relationship required to establish a latent state of lifetime persistence in the infected host, it is not surprising that herpesviruses belong to the continuously growing list of viruses that have developed strategies to defeat the antiviral effects of macroautophagy [45-47]. In fact, representatives of all three herpesvirus subfamilies encode proteins or induce cellular signaling pathways that affect macroautophagy.

The best studied example is HSV-1 [48]. A major breakthrough in understanding HSV-1 neurovirulence was the identification of ICP34.5 as an important neurovirulence factor that suppresses macroautophagy in infected cells via two different pathways: the dephosphorylation of translation initiation factor eIF $2 \alpha$ and the binding to the macroautophagy-promoting protein Atg6/Beclin-1 [27,33]. The double-stranded RNA-dependent kinase PKR stimulates macroautophagy induction through eIF $2 \alpha$ phosphorylation and ICP34.5 is able to antagonize this response by recruiting the host phosphatase $\mathrm{PP} 1 \alpha$ to dephosphorylate eIF2 $\alpha$. In addition, ICP34.5 can also bind to Atg6/Beclin-1 and might prevent it from entering the PI3 kinase complex to induce macroautophagy [49]. While the precise mechanisms by which macroautophagy protects against viral neuropathology are still unclear, it seems likely that macroautophagy functions to restrict viral replication. In ultrastructural studies, virions of the ICP34.5 deletion mutant have been detected within autophagosomes $[31,50]$. Moreover, metabolic labeling of viral proteins demonstrated increased rates of degradation in the ICP34.5 deletion mutant virus-infected cells compared with wild-type HSV-1 virus-infected cells [50]. These results indicate that virion targeting for xenophagic degradation is compromised by ICP34.5 [33].

Interestingly, other viruses that cause CNS disease also appear to suppress host macroautophagy. Human cytomegalovirus (HCMV), which belongs to the $\beta$-herpesvirus family and which causes severe CNS infections in neonates and immunocompromised adults, inhibits host macroautophagy, albeit with mechanisms different from those of HSV-1 [51]. In primary human fibroblasts, HCMV can block macroautophagy by activating the mTOR signaling pathway [52], which is known to suppress macroautophagy. Moreover, lithium chlorideinduced macroautophagy, which is mTOR-independent, is also suppressed by HCMV infection [53]. Thus, HCMV is able to inhibit macroautophagy via both mTOR-dependent and -independent pathways [51].

It is worth noting that in addition to these neurotropic viruses, other viruses, such as the oncogenic $\gamma$-herpesviruses that infect extraneural tissues, also encode inhibitors of Atg6/Beclin-1 and macroautophagy. Although the role of macroautophagy in $\gamma$-herpesvirus pathogenesis is not yet clear, these observations suggest that viral evasion of macroautophagy is probably not restricted to viruses that specifically infect the CNS. All members of the $\gamma$-herpesvirus family have in common that they express orthologs of Bcl-2, the cellular prototype inhibitor of apoptosis. These include orf16 of KSHV, herpesvirus saimiri and rhesus rhadinovirus, the BHRF1 and BALF-1 proteins of EBV, and the M11 protein of MHV68 [54]. In this context it is important to mention that apoptosis and macroautophagy are tightly interconnected and coordinately regulated. Besides preventing apoptosis, Bcl-2 also inhibits stress-induced macroautophagic cell death by binding to Atg6/Beclin-1 [55]. Several of the viral homologues of Bcl-2 have been shown to bind to Atg6/Beclin1 and to prevent it from binding to PI3 kinase complexes 
and, hence, suppress the initiation of macroautophagy $[22,56,57]$. Thus, vBcl- $2 \mathrm{~s}$ of $\gamma$-herpesviruses potentially inhibit both apoptosis and macroautophagy by binding to specific effectors of these pathways. This propensity of the $\gamma$-herpesvirus vBcl-2 proteins implies that macroautophagy might at least in part impact on viral persistence. Of note, it has recently been reported that maintenance of persistent MHV68 infection is impaired in a mutant virus lacking the anti-macroautophagic activity of $\mathrm{vBcl}-2$ compared to the wild-type virus [56], suggesting that MHV68, via vBcl-2, evades macroautophagy-mediated antiviral responses.

Besides targeting Atg6/Beclin-1, several herpesviruses including KSHV and herpesvirus saimiri can also suppress macroautophagy by expressing vFLIP, a homolog of cFLIP [29]. vFLIP, similarly to cFLIP, can bind to and prevent Atg3 from binding and processing LC3. This enzymatic activity of Atg3 is critical for the lipidation of Atg8/LC3 and the formation of autophagic vacuoles [58].

As mentioned above, EBV codes for two vBcl2 proteins (BALF1 and BHRF1) that are both expressed early during the lytic cycle, implying a protective role of these gene products during viral replication. In addition, both proteins are expressed early after infection of primary B cells [59], and BHRF1 also during the latent phase of infection [60]. Although it is currently not known whether these two proteins bind to Atg6/Beclin-1, these findings might indicate that EBV modulates macroautophagy at least during two phases of its life cycle.

Studies in other viral systems have demonstrated that virus replication, biogenesis, and egress can benefit from an increase in macroautophagy activity [61], and several herpesviruses including EBV, KSHV and varicella-zoster virus (VZV) have recently been demonstrated to not just suppress, but also induce macroautophagy. How VZV induces macroautophagy is unclear, but it does not seem to require late gene products, since the suppression of viral late gene expression with phosphonoacetic acid does not abolish VZV-induced macroautophagy [62]. The EBV latent membrane protein 1 (LMP-1) can induce macroautophagy in a dose-dependent manner [63]. Interestingly, the expression level of EBV LMP-1 also seems to be regulated by macroautophagy, as its level increases if macroautophagy is suppressed by short hairpin RNA (shRNA) targeting Atg6/Beclin-1 or Atg7 $[29,63]$. Furthermore, RTA, an essential viral protein for KSHV lytic reactivation, enhances macroautophagy and thereby facilitates lytic replication [64].

Thus, herpesviruses can affect macroautophagy either positively or negatively, depending on the virus, the virus' life cycle, and potentially the cellular context. However, with the exception of HSV-1, which suppresses macroautophagy to enhance its replication and pathogenesis, the role of macroautophagy in the life cycle of other herpesviruses still needs to be further elucidated.

\section{Conclusions}

Herpesviruses as one of the most successful families of pathogens have developed mechanisms to inhibit both innate and adaptive immune responses that rely on macroautophagy, and require this regulation for pathogenicity in vivo. These immune escape mechanisms of herpesviruses might, however, also affect functions that macroautophagy has beyond resistance to pathogens. Along these lines they could interfere with clearance of protein aggregates by macroautophagy during CNS infection $[65,66]$, compromise the role of macroautophagy in maintaining genome integrity as a protective mechanism against tumors [67] and impair protective mechanisms of macroautophagy against aging [68]. Thus, the pathomechanisms of chronic herpesvirus infections could potentially extend beyond direct transformation of cells, tissue destruction and immunopathology after lytic reactivation. As the list of herpesvirus associated diseases in humans grows, the potential for novel mechanisms of pathogenesis involving autophagy should be borne in mind.

\section{Acknowledgements}

Work in our laboratories is in part supported by the UK Medical Research Council to G.S.T.; the German Research Foundation (SFB455) to J.M.; the National Cancer Institute (R01CA108609 and R01CA101741), the Foundation for the National Institutes of Health (Grand Challenges in Global Health), the Swiss National Science Foundation (310030_126995) and the Sassella Foundation to C.M.

\section{Author details}

'School of Cancer Sciences and Medical Research Council Centre for Immune Regulation, University of Birmingham, Birmingham, UK.

${ }^{2}$ Department of Pediatrics, Technische Universität München and Helmholtz Zentrum München, German Research Center for Environmental Health, Munich, Germany. ${ }^{3}$ Viral Immunobiology, Institute of Experimental Immunology, University Hospital Zürich, CH-8057 Zürich, Switzerland.

\section{Authors' contributions}

GST, JM and CM wrote the manuscript. All authors read and approved the final paper.

\section{Competing interests}

The authors declare that they have no competing interests.

Received: 11 October 2010 Accepted: 5 January 2011

Published: 5 January 2011

\section{References}

1. Münz C: Enhancing immunity through autophagy. Annu Rev Immunol 2009, 27:423-429.

2. Mizushima N, Levine B, Cuervo AM, Klionsky DJ: Autophagy fights disease through cellular self-digestion. Nature 2008, 451:1069-1075.

3. He C, Klionsky DJ: Regulation mechanisms and signaling pathways of autophagy. Annu Rev Genet 2009, 43:67-93.

4. Hayashi-Nishino M, Fujita N, Noda T, Yamaguchi A, Yoshimori T, Yamamoto A: A subdomain of the endoplasmic reticulum forms a cradle for autophagosome formation. Nat Cell Biol 2009, 11:1433-1437. 
5. Yla-Anttila $P$, Vihinen $H$, Jokitalo E, Eskelinen EL: 3 D tomography reveals connections between the phagophore and endoplasmic reticulum. Autophagy 2009, 5:1180-1185.

6. Yen WL, Shintani T, Nair U, Cao Y, Richardson BC, Li Z, Hughson FM, Baba M, Klionsky DJ: The conserved oligomeric Golgi complex is involved in double-membrane vesicle formation during autophagy. $J$ Cell Biol 2010, 188:101-114.

7. Lynch-Day MA, Bhandari D, Menon S, Huang J, Cai H, Bartholomew CR, Brumell JH, Ferro-Novick S, Klionsky DJ: Trs85 directs a Ypt1 GEF, TRAPPIII, to the phagophore to promote autophagy. Proc Natl Acad Sci USA 2010, 107:7811-7816

8. English L, Chemali M, Duron J, Rondeau C, Laplante A, Gingras D, Alexander D, Leib D, Norbury C, Lippe R, Desjardins M: Autophagy enhances the presentation of endogenous viral antigens on MHC class I molecules during HSV-1 infection. Nat Immunol 2009, 10:480-487.

9. Hailey DW, Rambold AS, Satpute-Krishnan P, Mitra K, Sougrat R, Kim PK, Lippincott-Schwartz J: Mitochondria supply membranes for autophagosome biogenesis during starvation. Cell 2010, 141:656-667.

10. He C, Song H, Yorimitsu T, Monastyrska I, Yen WL, Legakis JE, Klionsky DJ: Recruitment of Atg9 to the preautophagosomal structure by Atg11 is essential for selective autophagy in budding yeast. J Cell Biol 2006, 175:925-935.

11. Ravikumar B, Moreau K, Jahreiss L, Puri C, Rubinsztein DC: Plasma membrane contributes to the formation of pre-autophagosomal structures. Nat Cell Biol 2010, 12:747-757.

12. Fujita N, Itoh T, Omori H, Fukuda M, Noda T, Yoshimori T: The Atg16L Complex Specifies the Site of LC3 Lipidation for Membrane Biogenesis in Autophagy. Mol Biol Cell 2008, 19:2092-2100.

13. Hanada $T$, Noda NN, Satomi $Y$, Ichimura $Y$, Fujioka $Y$, Takao T, Inagaki $F$, Ohsumi Y: The Atg12-Atg5 conjugate has a novel E3-like activity for protein lipidation in autophagy. J Biol Chem 2007, 282:37298-37302.

14. Nakatogawa $H$, Ichimura $Y$, Ohsumi $Y$ : Atg8, a ubiquitin-like protein required for autophagosome formation, mediates membrane tethering and hemifusion. Cell 2007, 130:165-178.

15. Xie Z, Nair U, Klionsky DJ: Atg8 Controls Phagophore Expansion during Autophagosome Formation. Mol Biol Cell 2008, 19:3290-3298.

16. Bjorkoy G, Lamark T, Brech A, Outzen H, Perander M, Overvatn A, Stenmark $H$, Johansen T: p62/SQSTM1 forms protein aggregates degraded by autophagy and has a protective effect on huntingtininduced cell death. J Cell Biol 2005, 171:603-614

17. Kirkin V, Lamark T, Sou YS, Bjorkoy G, Nunn JL, Bruun JA, Shvets E, McEwan DG, Clausen TH, Wild P, et al: A role for NBR1 in autophagosomal degradation of ubiquitinated substrates. Mol Cell 2009, 33:505-516.

18. Thurston TL, Ryzhakov G, Bloor S, von Muhlinen N, Randow F: The TBK1 adaptor and autophagy receptor NDP52 restricts the proliferation of ubiquitin-coated bacteria. Nat Immunol 2009, 10:1215-1221.

19. Ponpuak M, Davis AS, Roberts EA, Delgado MA, Dinkins C, Zhao Z, Virgin HW IV, Kyei GB, Johansen T, Vergne I, Deretic V: Delivery of cytosolic components by $\mathrm{p} 62$ endows autophagosomes with unique antimicrobial properties. Immunity 2010, 32:329-341.

20. Matsunaga K, Saitoh T, Tabata K, Omori H, Satoh T, Kurotori N, Maejima I, Shirahama-Noda K, Ichimura T, Isobe T, et al: Two Beclin 1-binding proteins, Atg14L and Rubicon, reciprocally regulate autophagy at different stages. Nat Cell Biol 2009, 11:385-396.

21. Zhong Y, Wang QJ, Li X, Yan Y, Backer JM, Chait BT, Heintz N, Yue Z: Distinct regulation of autophagic activity by Atg14L and Rubicon associated with Beclin 1-phosphatidylinositol-3-kinase complex. Nat Cell Biol 2009, 11:468-476

22. Liang C, Lee JS, Inn KS, Gack MU, Li Q, Roberts EA, Vergne I, Deretic V, Feng P, Akazawa C, Jung JU: Beclin1-binding UVRAG targets the class C Vps complex to coordinate autophagosome maturation and endocytic trafficking. Nat Cell Biol 2008, 10:776-787.

23. Jager S, Bucci C, Tanida I, Ueno T, Kominami E, Saftig P, Eskelinen EL: Role for Rab7 in maturation of late autophagic vacuoles. J Cell Sci 2004, 117:4837-4848.

24. Tanaka Y, Guhde G, Suter A, Eskelinen EL, Hartmann D, Lullmann-Rauch R, Janssen PM, Blanz J, von Figura K, Saftig P: Accumulation of autophagic vacuoles and cardiomyopathy in LAMP-2-deficient mice. Nature 2000, 406:902-906.
25. Fader CM, Sanchez D, Furlan M, Colombo Ml: Induction of autophagy promotes fusion of multivesicular bodies with autophagic vacuoles in k562 cells. Traffic 2008, 9:230-250.

26. Jacquemont $B$, Roizman B: RNA synthesis in cells infected with herpes simplex virus. $X$. Properties of viral symmetric transcripts and of doublestranded RNA prepared from them. J Virol 1975, 15:707-713.

27. Talloczy Z, Jiang W, Virgin HWt, Leib DA, Scheuner D, Kaufman RJ, Eskelinen EL, Levine B: Regulation of starvation- and virus-induced autophagy by the elF2alpha kinase signaling pathway. Proc Natl Acad Sci USA 2002, 99:190-195.

28. Delgado MA, Elmaoued RA, Davis AS, Kyei G, Deretic V: Toll-like receptors control autophagy. Embo J 2008, 27:1110-1121.

29. Lee DY, Lee J, Sugden B: The unfolded protein response and autophagy: herpesviruses rule! J Virol 2009, 83:1168-1172.

30. Leib DA, Machalek MA, Williams BR, Silverman RH, Virgin HW: Specific phenotypic restoration of an attenuated virus by knockout of a host resistance gene. Proc Natl Acad Sci USA 2000, 97:6097-6101.

31. Orvedahl A, Levine B: Autophagy and viral neurovirulence. Cell Microbiol 2008, 10:1747-1756.

32. Alexander DE, Ward SL, Mizushima N, Levine B, Leib DA: Analysis of the role of autophagy in replication of herpes simplex virus in cell culture. J Virol 2007, 81:12128-12134.

33. Orvedahl A, Alexander D, Talloczy Z, Sun Q, Wei Y, Zhang W, Burns D, Leib D, Levine B: HSV-1 ICP34.5 confers neurovirulence by targeting the Beclin 1 autophagy protein. Cell Host \& Microbe 2007, 1:23-35.

34. Lee HK, Mattei LM, Steinberg BE, Alberts P, Lee YH, Chervonsky A, Mizushima N, Grinstein S, Iwasaki A: In vivo requirement for Atg5 in antigen presentation by dendritic cells. Immunity 2010, 32:227-239.

35. Lee JS, Li Q, Lee JY, Lee SH, Jeong JH, Lee HR, Chang H, Zhou FC, Gao SJ, Liang C, Jung JU: FLIP-mediated autophagy regulation in cell death control. Nat Cell Biol 2009, 11:1355-1362.

36. Brazil MI, Weiss S, Stockinger B: Excessive degradation of intracellula protein in macrophages prevents presentation in the context of major histocompatibility complex class II molecules. Eur J Immunol 1997. 27:1506-1514.

37. Nimmeriahn F, Milosevic S, Behrends U, Jaffee EM, Pardoll DM, Bornkamm GW, Mautner J: Major histocompatibility complex class II-restricted presentation of a cytosolic antigen by autophagy. Eur $J$ Immunol 2003, 33:1250-1259.

38. Paludan C, Schmid D, Landthaler M, Vockerodt M, Kube D, Tuschl T, Münz C: Endogenous MHC class II processing of a viral nuclear antigen after autophagy. Science 2005, 307:593-596.

39. Leung CS, Haigh TA, Mackay LK, Rickinson AB, Taylor GS: Nuclear location of an endogenously expressed antigen, EBNA1, restricts access to macroautophagy and the range of CD4 epitope display. Proc Natl Acad Sci USA 2010, 107:2165-2170.

40. Leib DA, Alexander DE, Cox D, Yin J, Ferguson TA: Interaction of ICP34.5 with Beclin 1 modulates herpes simplex virus type 1 pathogenesis through control of CD4+ T-cell responses. J Virol 2009, 83:12164-12171.

41. Zhou D, Li P, Lott JM, Hislop A, Canaday DH, Brutkiewicz RR, Blum JS: Lamp-2a facilitates MHC class II presentation of cytoplasmic antigens. Immunity 2005, 22:571-581.

42. Chiang HL, Dice JF: Peptide sequences that target proteins for enhanced degradation during serum withdrawal. J Biol Chem 1988, 263:6797-6805.

43. Münz C: Antigen processing via autophagy-not only for MHC class II presentation anymore? Curr Opin Immunol 2010, 22:89-93.

44. Levine B, Kroemer G: Autophagy in the pathogenesis of disease. Cell 2008, 132:27-42

45. Lin LT, Dawson PW, Richardson CD. Viral interactions with macroautophagy: a double-edged sword. Virology 2010, 402:1-10.

46. Orvedahl A, Levine B: Viral evasion of autophagy. Autophagy 2008, 4:280-285.

47. Sir D, Ou JH: Autophagy in viral replication and pathogenesis. Mol Cells 2010, 29:1-7.

48. Koelle DM, Corey L: Herpes simplex: insights on pathogenesis and possible vaccines. Annu Rev Med 2008, 59:381-395.

49. He C, Levine B: The Beclin 1 interactome. Curr Opin Cell Biol 2010, 22:140-149.

50. Talloczy Z, Virgin HWt, Levine B: PKR-dependent autophagic degradation of herpes simplex virus type 1. Autophagy 2006, 2:24-29. 
51. Chaumorcel M, Souquere S, Pierron G, Codogno P, Esclatine A: Human cytomegalovirus controls a new autophagy-dependent cellular antiviral defense mechanism. Autophagy 2008, 4:46-53.

52. Jung $\mathrm{CH}$, Ro $\mathrm{SH}$, Cao J, Otto NM, Kim DH: mTOR regulation of autophagy. FEBS Lett 2010, 584:1287-1295.

53. Sarkar S, Floto RA, Berger Z, Imarisio S, Cordenier A, Pasco M, Cook L, Rubinsztein DC: Lithium induces autophagy by inhibiting inositol monophosphatase. J Cell Biol 2005, 170:1101-1111.

54. Polster BM, Pevsner J, Hardwick JM: Viral Bcl-2 homologs and their role in virus replication and associated diseases. Biochim Biophys Acta 2004, 1644:211-227.

55. Pattingre S, Tassa A, Qu X, Garuti R, Liang XH, Mizushima N, Packer M, Schneider MD, Levine B: BCl-2 antiapoptotic proteins inhibit Beclin 1-dependent autophagy. Cell 2005, 122:927-939.

56. E X, Hwang S, Oh S, Lee JS, Jeong JH, Gwack Y, Kowalik TF, Sun R, Jung JU, Liang C: Viral Bcl-2-mediated evasion of autophagy aids chronic infection of gammaherpesvirus 68. PLoS Pathog 2009, 5:e1000609.

57. Oh S, E X, Hwang S, Liang C: Autophagy evasion in herpesviral latency. Autophagy 2010, 6:151-152.

58. Tanida I, Ueno T, Kominami E: LC3 conjugation system in mammalian autophagy. Int J Biochem Cell Biol 2004, 36:2503-2518.

59. Altmann $M$, Hammerschmidt W: Epstein-Barr virus provides a new paradigm: a requirement for the immediate inhibition of apoptosis. PLOS Biol 2005, 3:e404.

60. Kelly GL, Long HM, Stylianou J, Thomas WA, Leese A, Bell Al, Bornkamm GW, Mautner J, Rickinson AB, Rowe M: An Epstein-Barr virus anti-apoptotic protein constitutively expressed in transformed cells and implicated in burkitt lymphomagenesis: the Wp/BHRF1 link. PLoS Pathog 2009, 5:e1000341.

61. Dreux M, Chisari FV: Viruses and the autophagy machinery. Cell Cycle 2010.

62. Takahashi MN, Jackson W, Laird DT, Culp TD, Grose C, Haynes Jl, Benetti L: Varicella-zoster virus infection induces autophagy in both cultured cells and human skin vesicles. J Virol 2009, 83:5466-5476.

63. Lee DY, Sugden B: The latent membrane protein 1 oncogene modifies Bcell physiology by regulating autophagy. Oncogene 2008, 27:2833-2842.

64. Wen HJ, Yang Z, Zhou Y, Wood C: Enhancement of autophagy during Iytic replication by the Kaposi's sarcoma-associated herpesvirus replication and transcription activator. J Virol 2010, 84:7448-7458.

65. Hara T, Nakamura K, Matsui M, Yamamoto A, Nakahara Y, SuzukiMigishima R, Yokoyama M, Mishima K, Saito I, Okano H, Mizushima N: Suppression of basal autophagy in neural cells causes neurodegenerative disease in mice. Nature 2006, 441:885-889.

66. Komatsu M, Waguri S, Chiba T, Murata S, Iwata J, Tanida I, Ueno T, Koike M, Uchiyama Y, Kominami E, Tanaka K: Loss of autophagy in the central nervous system causes neurodegeneration in mice. Nature 2006, 441:880-884.

67. Mathew R, Karp CM, Beaudoin B, Vuong N, Chen G, Chen HY, Bray K, Reddy A, Bhanot G, Gelinas C, et al: Autophagy suppresses tumorigenesis through elimination of p62. Cell 2009, 137:1062-1075.

68. Zhang C, Cuervo AM: Restoration of chaperone-mediated autophagy in aging liver improves cellular maintenance and hepatic function. Nat Med 2008, 14:959-965.

doi:10.1186/2042-4280-2-2

Cite this article as: Taylor et al:: Autophagy in herpesvirus immune control and immune escape. Herpesviridae 2011 2:2.

\section{Submit your next manuscript to BioMed Central and take full advantage of:}

- Convenient online submission

- Thorough peer review

- No space constraints or color figure charges

- Immediate publication on acceptance

- Inclusion in PubMed, CAS, Scopus and Google Scholar

- Research which is freely available for redistribution

Submit your manuscript at www.biomedcentral.com/submit 